\title{
Early Literacy Practices Go Digital
}

\author{
Eva Hultin, Maria Westman \\ Dalarna University, Sweden
}

\begin{abstract}
The aim of this study is to contribute to an understanding of how digitalization affects early literacy practices in terms of literacy teaching (methods, materials, routinized activities, etc.) and the use of literacy genres in digitalized writing. The study has an overall ethnographical design, where we as researchers, over the course of two years, follow a group of first grade teachers when they "go digital" in their literacy teaching. The study is theoretically influenced by New Literacy Studies, genre theory and multimodality. "Going digital" here includes both the new digital tools that the classrooms have been equipped with (e.g. computers, smart boards, projectors, etc.) and the use of a specific early literacy method, learning to read through writing on computers - without using a pencil. The method involves a change from children learning to read and write by using textbooks for reading and pencils for writing to using computers from the start. The children's own texts are used as important reading material. When children use digital writing tools their texts become longer and they also use a wider range of literacy genres, specifically more factual genres.
\end{abstract}

\section{Introduction}

There is a broad social consensus that it is important that young people, through the educational system, acquire extensive literacy skills in order to be able to participate both as professionals and as citizens' in future adult life. This social consensus is expressed in various national and international policy documents on education, such syllabi and curricula at national levels and, internationally, for example OECD's policy paper on Definition and Selection of Key Competencies [1]. This consensus is constituted by an understanding that virtually every sphere of society is permeated by written language today. This means that it is difficult to find a profession where the need for using written language in one form or other does not exist. In the same way, it is difficult for citizens to use their democratic rights if they have not developed advanced literacy skills. Those who do not adequately learn to read and write at school are in danger of becoming both professionally and politically marginalized [2].

While society undoubtedly is making increasing demands on individuals' literacy skills, the trend in recent years has been an increasing amount of students leaving compulsory school without adequate literacy competence. In Sweden, for instance, $12 \%$ of the students left compulsory school without grades in Swedish in 2010 (compared to 11, 2\% in 2009) [3]. It is not clear from the report just how many of those students' school performance was due to their lack of literacy skills, but earlier studies show clearly the importance of children succeeding in early literacy education[4].

Thus, from a societal and individual perspective, it is important to find teaching methods that all children, early on in school, can benefit from in order to be able to reach adequate literacy goals. This is also the motive for studying the school development project "Learning to read through writing on computers", where a group of 30 primary school teachers (first grade), in a Swedish municipality, "go digital" in their literacy teaching. "Going digital" here includes both the new digital tools that the classrooms have been equipped with (e.g. computers, smart boards, projectors, etc.) and the use of a specific literacy method: learning to read through writing on computers, without using a pencil, thereby implying a change from teaching children to read and write through using textbooks (reading) and using a pencil (writing) to teaching the children to read through writing on computers (without using pencils) from the start. The children's own texts are used as important reading material. The computers are equipped with speech synthesis programs, talking keyboards, spelling programs, alphabetic playful programs etc. Furthermore, the classrooms have been equipped with a smart board and a projector. The teachers are included in a school development project within the municipality which is led by a special needs coordinator. Some teachers in this municipality have been working with this method for the last 8 years; however, most teachers in our study are new beginners. The experienced teachers claim that the numbers of children with reading and writing disabilities have decreased, even though no research on their work has been done to verify this. However, the main research interest of this study is to analyze 
changes in literacy practices (methods, materials and genres etc.) due to digitalization.

\section{Aim of study}

The aim of this study is to contribute to an understanding of how digitalization affects early literacy practices in terms of literacy teaching (methods, materials, routinized activities, etc.) and the use of text genres in digitalized writing. This aim generates the following research questions:

1) What literacy methods and materials are used after digitalization in early literacy teaching?

2) What routinized activities are organized in the literacy teaching after digitalization?

3) How do the possible changes in digitalized literacy teaching affect children's text production?

4) What text genres do children use in their digitalized writing?

\section{Methods and design}

This article focuses on two main areas of the digitalization of early literacy teaching: changing focus in literacy teaching and a change in the use of text genres when literacy teaching is digitalized.

The results presented here are based on several different empirical materials. Firstly, we observe the teachers' monthly project meetings, led by a coordinator in which the teachers in the project meet and discuss the progress of the project. During these meetings, field notes are written when the project coordinator leads discussions on present situations and when the teachers ask questions and describe and discuss new possibilities, challenges and problems that they have encountered in their specific classrooms concerning digitalization and early literacy teaching. During these meetings, informal discussion between the researchers and many of the teachers also takes place.

Secondly, eight of the teachers have been selected for qualitative interviews, which have been conducted at least once per teacher. These interviews focus on how teachers describe the ways their teaching practices have changed after the digitalization of literacy teaching.

Thirdly, classroom observations in two different classes during two periods of one week each have been conducted. Here, specific interest has been paid to situations where digitalization and literacy are in focus. Apart from field notes, literacy events have been photographed and some teaching situations have been documented by filming.

Finally, text material has been collected. Texts from 12 different children, six from each of the two observed classes, have been gathered. The results presented here are based on a collection of all the texts produced between August and April from the 12 children in first grade. In all, 417 texts have been collected and analyzed for both form and content.

\section{Theoretical background and earlier studies}

Theoretically, this literacy study is grounded in New Literacy Studies, where literacy practices are seen as heterogeneous, pluralistic phenomena $[5,6$, 7]. This choice of theoretical perspective is due to the fact that we are studying literacy practices undergoing change. These particular literacy practices are situated within an educational system regulated through school laws and the curriculum, and both national and local educational documents. Furthermore, the literacy practices in question are also embedded in teaching traditions with long historical roots.

Concerning literacy teaching, historically, there have been mainly two dominating teaching traditions: the phonic tradition [8] and the whole language tradition $[9,10]$. These two traditions contain different views on both literacy development and teaching methods. The phonic tradition emphasizes that literacy education should start by pupils encountering one letter at a time, presented in a pre-decided order. These letters are then put together into words and sentences. This perspective goes from parts to whole language and knowledge of letters and phonic awareness are essential. Within this perspective, there is a divide between orality and literacy, where literacy should be presented in a structured way. The whole language tradition stresses the opposite. Here it is emphasized that literacy education should start in whole texts which are subsequently broken down into sentences and words. In this perspective, pupils' experiences and interests are the starting point. The whole language tradition understands literacy development as something that comes naturally if children encounter written language in meaningful situations. The struggle between these two traditions has been seen as a literacy war.

However, some scholars as well as practitioners assert that this "literacy war" is long since over, and that literacy teaching today cannot be described as either/or. It has been argued that literacy teaching should instead consist of a synthesis of the two traditions [11]. In this article, however, we use the descriptions of the two polarized literacy traditions analytically, for discussing the possible changes in literacy teaching due to digitalization. Earlier studies show that schools historically have shown a reluctant approach to using new technology in their traditional ways of teaching [12]. It has been pointed out that important new technology has the potential to be 
useful in teaching (radio, television, tape recorder, and video etc.), and is often talked about as a possibility for reforming teaching to a great extent. However, this has not been the case, according to Cuban [12]. He points out that if new technology has been used in teaching it has only played a subordinate role, conditioned by the traditions of teaching.

Even though the schools and classrooms in this study have recently undergone a digitalization in terms of more computers, smart boards, projectors, etc., computers as such are, of course, not something new in schools in general. In the 1990's many schools in Sweden already had computers installed in their classrooms. The advantages of using computers in early literacy teaching have been discussed earlier; of particular note is the Norwegian researcher Arne Trageton [13]. He developed a method for early literacy learning where the pencil is exchanged for the computer. Trageton shows that pupils who learn to write and read on computers have better results further on in school than age peers who have encountered more conventional literacy methods (phonics and whole language). In our study the teachers also claim that pupils who use computers for literacy learning are ahead of pupils who encounter more conventional literacy methods.

So far, there are similarities between Trageton's findings and the project in the Swedish municipality in focus in this study. However, there are some crucial differences, not least due to the technological development during the decade since Trageton conducted his study. Now there are more advanced software and hardware such as speech synthesis, talking keyboards, and a range of different pedagogical literacy programs. Furthermore, the method used in this case study also differs; a key concept in Trageton's method is a sort of emergent writing, or experimental writing, where children start typing letters randomly (prewriting), and, successively, discover how to write more conventionally, while the method here studied is based on, as we shall see below, using sample texts from the very beginning.

In order to understand the literacy practices, genre theories are used to analyze and understand the text production to which the digitalization of early literacy learning leads. Genre, as a concept, is in many ways problematic, and the broad discussion of the notion of genre indicates different ways of understanding it. Basically, genre can be seen as something based more or less on textual factors and/or based on relations between text and context. The more textual concept of genre is represented by The Sydney Genre School, influenced by Halliday's [14] systemic functional grammar, where stages, structure, and the aim of the text classify the genre. Martin defines genre as "a staged, goal-orientated, and purposeful social activity that people engage in as members of their culture" [15]. In line with this they describe typical school genres: narratives, recounts, reports, instructions, explanations, and arguments [16].

In more contextual ways of understanding, genre can be classified based on rhetorical practices [17] or as classes of communicative events with common communicative purposes identified by those who are using them [18]. In line with Miller and Swales, the rationale of the concept of genre lies in understanding the genre as open for transformation and redesign due to the literacy context.

Here the starting point is the school genres represented by the Sydney Genre School (above), at the same time as genres are understood as being socially constituted and plastic phenomena that change into new forms (hybridization) as agents use them for new purposes and in new situations. This epistemological understanding of genre is more in line with Miller and Swales.

As a complement to genre theory, we turn to research on multimodality, reminding us of the importance of digitalization in terms of new semiotic resources in text production [19]. These new semiotic resources not only change the conditions for text production in a radical sense, but also open possibilities for creating multimodal texts that include pictures and sounds. These multimodal possibilities most certainly change the genres in use.

\section{Results}

In this section, the results of this study will be presented. These show that teachers have radically changed their literacy teaching approach by going digital. These changes can be categorized into two areas. The first area is a change in focus in teaching from forming and sounding out letters to producing texts. The other area points at a shift in the use of genres within the teaching of reading and writing: the students seem to both read and write in different genres when going digital.

\subsection{Changing focus in literacy teaching}

Most of the teachers in the study describe how they have gone from a letter-based literacy teaching to a teaching focused on text production. In their earlier letter-based teaching, the teacher introduced one letter a week to the children, emphasizing sounding out the letter and forming the letter in handwriting. The sounding out of letters was done both as a recurrent collective teacher-led activity in class, where the teacher sounded out the letter, or words, and the children chanted after, and as an individual activity, where children sounded out letters in their benches while reading, sometimes under the teacher's surveillance. 
The forming of letters in handwriting was also done through whole-class activities in which the teacher pointed out how to hold the pen, where to start writing the letter, etc. After the teacher-led session on how to form a certain letter, the children were to practice forming the letter by writing the single letter over and over again. Furthermore, the children could also get assignments where they should trace the specific letter in newspaper headlines, cutting them out and pasting them on a piece of paper. "It could take several weeks before the children could put together the letters into a word," says one of the teachers. Clearly, most teachers in this study formerly conducted phonicoriented literacy teaching.

However, after digitalization their teaching methods have radically changed, as they have moved to a text production approach in their literacy teaching. This means that the children start off writing whole texts on the computer from the very beginning. In order to write whole texts, the children are offered scaffolds in terms of sample texts. These texts resemble lists, such as: I can ...., I want to... My family is... One representative example of this is found in Figure 1.

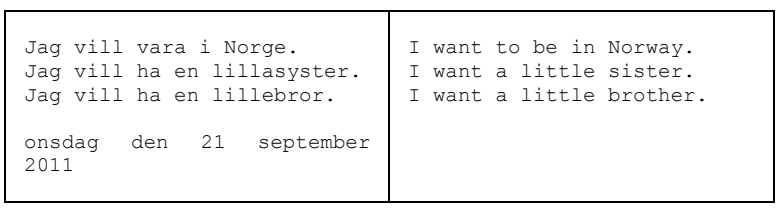

Figure 1. I want...

Texts like this all emanate from experiences the children have and are well acquainted with. In terms of genre, we call the text example above a personal report (see below).

Thus, working with one letter at a time is now left out. Sounding out letters is no longer part of the formal teaching in collective teacher-led activities; the sounding out is instead integrated in the children's writing processes through the speech synthesis program and the talking keyboard. As soon as a child presses a key, he/she, in the headphones, hears the sound of the letter that he/she is writing. In that way, sounding out is always present during their writing, even though it is no longer made an object of formal teaching.

Although the above-mentioned teacher-led activities of the letter-based literacy classroom have vanished, teacher-led activities occur on a daily basis even in the digital text-producing classroom. These class activities support both children's individual writing as well as different forms of collective writing in class. When it comes to the children's individual writing, these activities create prerequisites for writing in terms of knowledge on both the subject matter (the content of the text), the form of the text, and how to use the digital tools (e.g. attaching pictures to the text, saving the text and the file, etc.).

Examples of those activities, which have become routinized as they recur on at least a weekly basis, are the ones initiating children's individual writing, e.g. reports on animals (see below). They start with the teacher giving a small lecture on the subject. In some cases, they watch a short documentary on the animal in question (e.g. the bear, the wolf, the mouse, etc.). After that, the teacher starts a dialogue with the children, establishing what facts the documentary brought up. Most teachers make a mind map on the white board with facts from the documentary, and sometimes children also add facts on the animal from their own experience. When all the facts on the animal are put on the table, so to speak, the children start writing their own texts in the genre reports on animals.

A routine has also been formed for the activities when the teacher and the children write a text together. Here the teacher functions as the class's secretary, as he/she writes the sentences that the children tell her/him to write. As the teacher types on a computer connected with a projector, the children can see, on the white board, how the text grows sentence by sentence. When all children have contributed to the text with one or more sentences, the teacher reads the text out loud, and the class discusses if anything should be changed. These kinds of meta-discussions on texts, both on their form and content, are another noticeable change in digitalized literacy teaching as a whole, and not only in the discussions related to collective writing.

This increase of meta-discussions is also something that many teachers point out in relation to pupils' individual writing. They stress a greater awareness of both form and content when children produce texts on the computer, since using computers and different word processing programs, e.g. spelling programs, visualizes errors in the text by specifically marking it. Misspellings and grammatical errors are underlined, which the children notice. This leads to more extensive discussions on both the form and the content of a text. Teachers also stress the difference from before, when changing in a text was difficult. Erasing in texts before digitalization was something that often led to papers tattered and torn, and malcontented children. Writing on computers makes it physically easier to write, erase and re-write.

The interviewed teachers emphasize how children can master their texts with the new technology in ways that was impossible for children before the digitalization. For instance, correcting texts is now an activity initiated by the children, as mentioned above, when they see the red or green lines under a word; previously, these discussions, when they happened, were initiated by the teacher, as the children could not see mistakes in their texts 
themselves. Moving sections of text, which is easily done on a computer but more difficult on a piece of paper, also gives children a sense of how to structure content in a text. In this way, the digitalization of early literacy teaching enables teachers and children to develop a process writing approach from the very beginning of their literacy process.

The texts the children write also change in other ways. Not only are whole texts produced at an earlier stage than before, but the texts produced are also longer and more multimodal. Due to the digitalization children are able to produce much longer texts, without being able to fully master all the letters. Writing on computers simplifies writing, since it does not demand highly developed motor skills. The produced texts are also more multimodal. Even though drawings have been commonly used together with early literacy learning, this method invites more different modalities into the making of texts. Using a computer offers the opportunity to use pictures, sound, films etc. in text production, which opens up for a range of new forms of producing text. However, the most common modality found in the material is a text illustrated by a picture, copied and pasted into the text written by the child.

\subsection{Change in use of literacy genres}

Many teachers point out that, due to the shift from letter-based teaching to digitalized-text-based teaching, the use of different text genres has both changed and broadened.

Digitalizing early literacy learning hence leads to a change in the use of text genres. Historically, one of the most used genres in primary school has been the narrative or story. Another common school genre in Swedish primary schools is händelseboken a form of diary, where events are described and illustrated on a weekly basis, formerly used by many of the teachers in the study. These genres are not used as much as they were before, according to the teachers.

In the study, the text material consists of 417 collected texts, written by 12 different children from two different first grade classes. The texts are produced between August and April in one school year. The texts have been categorized as both factual and fictional texts divided into six different text genres, analyzed as school genres: narratives, reports, recounts, letters, poems, and performative genres. Some of the genres are then divided into subcategories, here called sub-genres. Some texts are also composed by mixtures from different genres, hybrid genres. The distribution between the different genres is illustrated in Table 1; these two children's texts are representative for the whole body of material.
Table 1. The distribution of genres in two pupil's texts

\begin{tabular}{llrrrrr}
\hline School & Report & Recount & Narrative & Letters & Poems & Performative \\
\hline $\begin{array}{l}\text { School } \\
\text { A : }\end{array}$ & 18 & 3 & 7 & 2 & 1 & 7 \\
$\begin{array}{l}\text { Girl 3 } \\
\begin{array}{l}\text { School } \\
\text { B: }\end{array}\end{array}$ & & & & & \\
Boy 1 & & 3 & 5 & 1 & 3 & 3 \\
\hline
\end{tabular}

In the material, the factual text genre report is most frequently represented. The genre characteristics of the report are: a set of facts, organized by classification or part-whole relationship, generic participants, relational and existential processes used to describe characteristics and to present generalization, material and behavioural process clauses to describe activity, timeless verbs in simple present tense [16].The fictional text genre narrative is the second-most frequent genre, even though it is far from being as common as the report. The genre characteristics of the narrative are: events in relation to chronology, plot, conflict, and solution [16]. The third most common texts genres are the personal text genre recount and a more fictional type of text, here called performatives. The characteristics of recounts are: a retelling of a sequence of events, and drawing on personal experience [16]. We have classified texts as performative when they contain dialogue or monologue that could be part of a performance but are neither narratives, recounts nor poems. The less frequent genres are the personal genre letters and the fictional genre poems. The characteristics of the genre letter are: greeting phrases both initially and at the end, personal questions, personal accounts, and address. Poetry is not characterized by rhyme here, but rather by rhythm and typographic form as well as a more fictitious content. Here two sub-genres illustrate how these text genres may appear: the personal report and the report on animals.

The first type of texts introduced here, we have classified as personal report which is a sub-genre to reports. The texts follow a certain pre-decided form, which often resembles a list. The form as well as the linguistic features (grammar, style etc.) indicate a non-fictional text based on facts, even though the content here is personal. The content of these texts are based on the children's own notion of themselves and their own experiences and most texts describe personal knowledge that the child has. Figure 2 illustrates one of these texts, with a translation into English. 


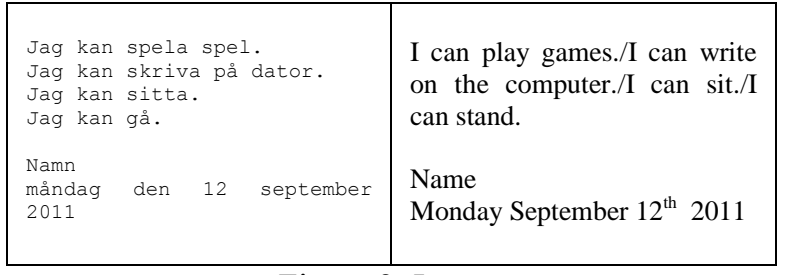

Figure 2: I can...

The texts are constructed around phrases such as: I can..., I like..., I have..., My family is.... In that way, verbs in the simple present tense are used. The processes used are relational, as in I have and I am which here is used for describing personal characteristics. Other processes used are material, as in I can, which illustrates how to represent activity. All these processes are typical characteristics of reports, whereas the mental processes as in I like is not a specific linguistic feature of the report. But in these texts, this feature is used for representing personal experiences.

Another very commonly used genre is the subgenre reports on animals. In fact, this sub-genre is the most used genre found in the material. In these factual reports different animals are described. This sub-genre in many ways resembles the factual report described above, both in form and content. Here, each text presents one animal generically, with general facts describing breeding, food, and appearance about the specific animal. In Figure 3, a text about the fox illustrates these kinds of texts.

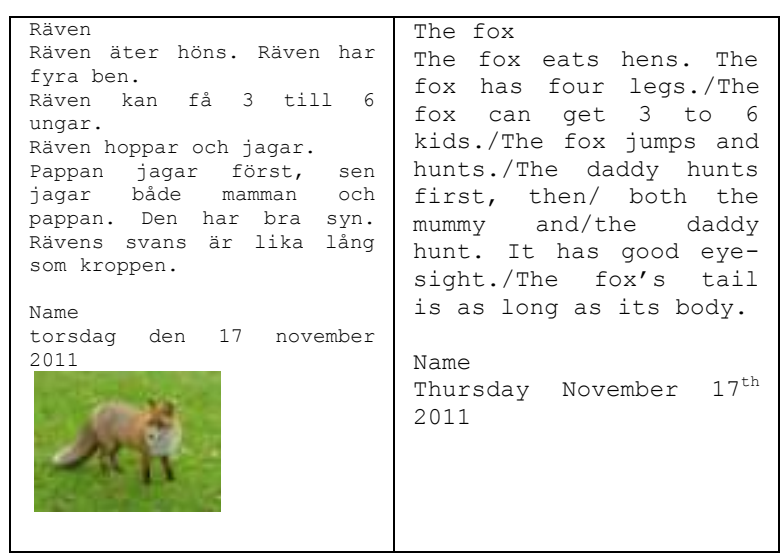

Figure 3. The Fox

The linguistic feature typical for the report used in figure 3 above is the use of relational processes: "The fox has four legs", "It has good eye-sight" "and "The fox's tail is long" [emphasised ours]. Here it is used to present characteristics of the described animal. Other processes found here are material: the fox eats, jumps and hunts [emphasised ours]. These material processes are used to present activities typical of the animals' behaviour. The clauses are constructed around generic participants, here: the fox. The text is also presented in the simple present tense. Altogether this establishes the text as a report on animals.

The illustration in Figure 3 also shows a common way of using multimodal artefacts as a part of the text, where a picture is pasted onto the written text. Some examples of reports on animals were produced quite soon after the children had started to write texts. These early reports are often shorter and more list-like and often resemble the texts representing the personal report sub-genre.

A third example of a text genre used after the digitalization of literacy teaching is the genre here called performative. This genre is not identified in accordance with any of the school genres identified by the Sydney Genre School. We have classified texts as performative when they contain dialogue or monologue that could be part of a performance but cannot be classified as narratives, recounts or poems. The text genre performative is firstly recognised by its form of direct address in the form of a monologue. The participant is presented in the first person, I. The texts classified as performatives can be both factual and fictitious content-wise, i.e. the participant or speaker in the text can be the child him/herself, a specific animal, a cartoon, or a fictitious character. A common feature among the performatives found in the material is that many of the texts are written inside a balloon and some in the form of a riddle. In Figure 4, one of these texts is illustrated.

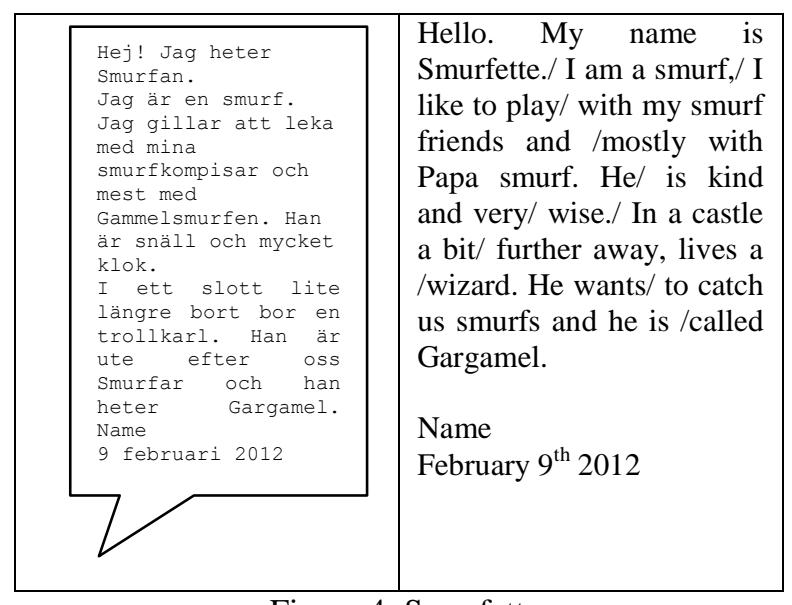

Figure 4. Smurfette

The performatives are, consequently, not categorized only by specific grammatical or linguistic features, but more on the dialogic or monologic approach to the text as well as the more multimodal form of the text. Here both text and form cooperate, and the digitalization itself is more or less a condition for the use of the particular genre. In that way, this text genre is using multimodality to a greater extent than just pasting a picture on the written text. Here, the balloon offers a restricted form for writing, but at the same time, the balloon 
itself is the very condition for the existence of the text genre. This modality, together with the written text, generates meaning and offers a way to interpret the text as a genre of its own.

To sum up, a change in use of genres can be seen as a result of introducing computers in early literacy teaching. Some genres are used to a greater extent than before, preferably more factual genres as personal reports and reports on animals, while some are used less frequently; in particular, the händelseboken (see above) is at this stage left out. Some new genres also appear as a result of the possibilities of more multimodal texts that digitalization offers.

It is notable that the teaching method uses sample texts as a form of scaffolding structure for the pupils. In a way, these prescribed forms restrict both form and content, but at the same time offer a way of performing writing to the children who still have not fully mastered the ability to write without help and support. This explains why many texts resemble each other and are classified into the same genre. This also can explain why some specific genres are used more often than others, and also why more fictional genres and expressive writing are not central in this specific context.

\section{Conclusions}

The results of the study show that the studied literacy practices have changed, both in terms of literacy teaching (methods, material, routinized literacy activities) and in terms of text production and genre.

Most teachers have abandoned a letter-based literacy teaching in which the focus was on sounding out letters and forming letters in handwriting for a literacy teaching focused on text production. Handin-hand with these changes of literacy methods come changes in the content of routinized literacy activities in class, in both the teacher-led whole-class activities and the individual activities. Sounding out, for instance, is not made an object for formal teaching in teacher-led activities in class. Instead, the contents of whole-class activities after digitalization aim at giving prerequisites for the children's individual writing, through discussing the texts' form and content. The collective writing that takes place in the whole-class activities also gives the children important experiences of writing that they can benefit from in their individual writing later on. Digitalization has definitely played a crucial role in these changes. For teachers, being able to use a computer projected on a big screen for all children to see makes it possible for children to follow how a text is built up sentence by sentence. They can also see, and suggest, how things easily can be changed and moved in the text. Still, even if the technology enables this change, it does not guarantee it.
Changing the teaching from a more mechanical approach where children chant sounds after the teacher or write one letter at time in long rows into a more dialogic teaching where children and teacher write and discuss texts together is possibly ultimately a consequence of the teacher's intention to change the teaching to a more dialogic mode.

Having said this, the results show undoubtedly that the digitalization plays a decisive role for changing the conditions for writing and rewriting texts for children. As been pointed out, it is physically easier for children to write on the computer, and, as a consequence, children write longer texts. It is also easier to make changes in a text when writing on computers. Using spelling and grammar programs, the children also notice when something needs to be corrected in the text. Thus, the initiative for correcting texts comes more often now from the children than from the teachers. In that way, children seem to have more agency when writing texts on the computer than they did before, as they can master their texts and also take the initiative for getting help to correct them when they find it necessary.

The changed conditions of writing might also bring about a change in conception of what it means to be a writer. The earlier common literacy practice in schools, in which children (usually in grades higher than first grade) were given a blank sheet of paper and were asked to write an essay on their summer holiday, implied a conception of a writer as someone who could turn on creativity as soon as he/she got a pencil in hand - without any preparation or opportunities to rewrite afterward. This approach to writing much resembles the conception of the writer as a genius, an idea with roots in the romantic literary movement during the $19^{\text {th }}$ century. Now, when the children and teacher first prepare for writing by going through important facts about the content, and then the children have many opportunities to discuss their text and change it, the concept of being a writer that is implied is more process-oriented. Being a writer is not limited to few brilliant geniuses, but rather something we all can be as long as we write and rewrite our texts in dialogue with others.

In conclusion, when it comes to the change in use and production of text genres after the digitalization of literacy practices, our material shows that many texts produced resemble each other. In the material we have found six different text genres: narratives, reports, recounts, letters, poems, and performative genres. Most of these genres resemble the school genres identified by the Sydney Genre School, but some of the genres are not found within that system of categorization. Letters, poems and performatives are additional genres found in our material. These genres are all fictional. However, these texts are not common in the material. Here the expressive and free 
writing is not in focus, but other more non-fictional text genres are. This probably is a result of digitalization.

The most common genres found in the material are factual types of reports on different matters: animals, holidays or the pupils themselves. Here the resemblance to other genre classifications [16] is more obvious, even though some differences can be noticed (see above). These findings also differ from what the teachers used to describe as commonly written texts before digitalization, where expressive and free writing were the most common ways of writing. This change in preferred genres used in schools also marks the change of the implied conception of the writer. The writer as a genius obviously wrote in expressive genres, where his brilliance could shine.

Notable is that the factual texts emanate from lessons where the children use writing as a learning tool in at least two perspectives. While learning about the fox or the rabbit, reading and writing is introduced and practiced simultaneously. This integration is facilitated by both the digitalization itself and the structured and predecided sample texts.

Both the digitalization and the sample texts help the children to write a more complex text than they would have been able to write before, when using a pencil for writing. The sample texts as scaffolds support the construction of a certain genre, while the actual writing is facilitated by having to press a key on the keyboard instead of forming letters with a pencil. In that sense, it is easier to perform actual writing after digitalization.

On the other hand, the sample texts can also limit the pupils' writing. An interesting question is how much the children's agency has actually changed after digitalization. The writing itself is more easily mastered by the child, but the restricted forms can also work as a hindrance. There are examples of children who already are able to write long texts when they start school, who adapt to the restricted forms and start to write less developed texts. In that way, the genres offered can function as both an opportunity and a limitation, depending on the actual child. The digitalization itself cannot bridge these hindrances. Here the teacher has a crucial role, to open didactical opportunities that are as possible.

Let us return to the question on literacy traditions. We have already mentioned that the teachers left a letter-based tradition (phonics) for a text-production-based approach in literacy teaching. Can this new approach be understood as part of the Whole Language literacy tradition? The new approach is clearly text-based, as the children write whole texts from the beginning and dialog is central to the process. But since correctness and phonological awareness are also important, it is difficult to classify the method as either belonging to the phonics tradition or the whole language tradition.
Instead, this method perhaps can be described as a synthesis of the two traditions. The computer offers a more direct and individual response, where phonological awareness comes from the direct response from the computer programs. At the same time, the whole text is constantly in focus, and the text production starts in the children's own experiences. Thus, the teachers not only adapt existing methods but also form a new literacy tradition, which can be understood as a synthesis of the two earlier literacy traditions, and with obvious elements of genre teaching. In this perspective, digitalization has not only simplified the act of writing, but also led to a new way of teaching early literacy.

\section{References}

[1] OECD's Definition and Selection of Key Competencies (DeSeCo) (2005).

[2] Street, B. (1995) Social Literacies: critical approach to literacy development, ethnography and education. Longman, London.

[3] Swedish National Agency for Education report 350, (2010).

[4]Liberg, C. "A close reading of reading comprehension among Swedish students in grade 4". http://www.iea.nl/iea_irc.html (November 20, 2012).

[5] Barton, D. (2007) Literacy - an Introduction to the Ecology of Written Language. Blackwell, Malden.

[6] Kress, G. R. (2003) Literacy in the New Media Age. Routhledge, London.

[7] Heath, S. B. (1983) Ways with Words: Language, Life and Work in Communities and Classrooms. Cambridge university press, Cambridge.

[8] Adams, M.J. (1990) Beginning to Read. Thinking and Learning about Print. MIT press, Massachusetts.

[9] Clay, M. M. (1993) Reading Recovery. A Guidebook for Teachers in Training. Heinemann, Auckland, New Zeeland.

[10] Smith, F, (1988) Understanding Reading: a Psycholinguistic Analysis of Reading and Learning to Read. Earlbaum, Hillsdale, N.J.

[11] Fredrickson, N and T Cline (2002) "Literacy" in: Special Education Needs, Inclusion and Diversity - a textbook. London, Open university press, pp 298-332.

[12] Cuban, L. (1986) Teachers and Machines: The Classroom Use of Technology since 1920. New York: Teachers Collage Press. 
[13] Trageton, A. (2003) $\AA$ skrive seg til lesing - IKT $i$ Småskolen. Universitetsforlaget, Oslo.

[14] Halliday, M. A. K. (2004) An introduction to functional grammar. 3. ed. London: Arnold.

[15] Martin, J. R. (1984) "Language, register and genre". In F. Christie, ed., Children Writing: Reader. Geelong, Via: Deakin University Press, pp. 21-29.

[16] Schleppegrell, M. J. (2004). The language of schooling: a functional linguistics perspective. Mahwah, NJ: Lawrence Erlbaum, pp. 84-85.

[17] Miller, C. R. (1984) "Genre as Social Action". Quarterly Journal of Speech 70, pp.151-167.

[18] Swales, J. M. (1990) Genre Analysis: English in academic and Research Settings. Cambridge: Cambridge Univ. Press.

[19] Jewitt, C. (ed.) (2011). The Routledge handbook of multimodal analysis. London: Routledge. 